\title{
O cinema moçambicano pós-colonial: outros olhares, outros discursos.
}

\author{
Alex Santana França ${ }^{1}$
}

RESUMO: O presente trabalho propõe uma discussão sobre o cinema moçambicano pós-Independência, no intuito de discutir a própria importância do cinema no processo de construção e afirmação da identidade nacional moçambicana. O objeto de estudo em questão trata-se do filme $O$ grande bazar, de Licínio Azevedo, lançado em 2006. A análise fílmica também contemplará o modo de construção narrativa e algumas recorrências temáticas, a fim de destacar traços formais, estéticos e de conteúdo.

ABSTRACT: This paper proposes a discussion on the Mozambican cinema post-Independence, in order to discuss the very important film in the construction and affirmation of Mozambican national identity. The object of study in question comes from the movie $O$ grande bazar by Licinio Azevedo, released in 2006. The film analysis will also include the mode of narrative construction and some thematic recurrences in order to highlight features formal, aesthetic and content.

PALAVRAS-CHAVE: Cinema moçambicano; Identidade nacional; Estética fílmica.

KEYWORDS: Mozambican cinema; National identity; Filmic aesthetics.

De todos os países africanos de língua portuguesa, Moçambique é o que possui a filmografia mais variada e um conjunto de realizadores com características diversas que continua, até hoje, a produzir, apesar de não ter mais o apoio do Estado. Para Mahomed Bamba (2007, p. 19), o cinema

está longe de ser um luxo na África. Um cinema com ambições modestas, sem forçosamente se limitar a um cinema autoral, autossustentável no polo da produção e da distribuição ou apoiado por esforços políticos e que seja proporcional à capacidade econômica de cada nação já é suficiente para atender às demandas das populações locais, cada vez mais sedentos por imagens.

De acordo com o antropólogo moçambicano Luís Cabaço (2005, p. 12), a primeira produção cinematográfica realizada em Moçambique foi Chaimite, do diretor português Jorge Brum do Canto, em 1950, obra que exaltava o início do ocupação colonial portuguesa no país. Em seguida, foi criada por Antonio Melo Pereira, que

\footnotetext{
${ }^{1}$ Professor, pesquisador e escritor, graduado em Letras (UFBA), Especialista em Metodologia do Ensino de História e Cultura Afro-brasileira e Indígena (FACE) e Mestre em Literatura e Cultura (UFBA). Aluno do Doutorado do Programa de Pós-graduação em Cultura e Sociedade da Universidade da Bahia. E-mail: alexsfranca@yahoo.com.br
} 
trabalhou como operador de câmera naquele filme, uma produtora, firmando base no solo moçambicano. Ela produziu um cinejornal mensal denominado "Atualidades de Moçambique" e alguns documentários.

Na segunda metade da década de 1950, o português Courinha Ramos criou o primeiro laboratório e o primeiro estúdio de Moçambique, que também lançou um cinejornal, o "Visor Moçambicano" e realizou alguns documentários. Na década seguinte, o cineasta Luís Beja fundou a Beja Filmes, produtora que prestava serviços principalmente para o governo e empresas privadas. Ela entrou no mercado oferecendo filmes a cores.

Em 1971, uma produtora luso-espanhola, a Telecine-Moro estabeleceu-se em Moçambique investindo no mercado publicitário. Nesta mesma época, Courinha Ramos produziu o filme Limpopo, dirigido por Eurico Ferreira. Em 1973, ele também realizou Deixem-me ao menos subir às palmeiras, baseado num conto do escritor Luís Bernardo Honwana, filme de denúncia do colonialismo em formato $35 \mathrm{~mm}$, preto e branco.

Os cineclubes em Moçambique foram fundamentais para a consolidação da produção cinematográfica local. Eles ganharam tanta vitalidade que resultou na realização de um festival, com destaque para os cineastas Faria de Almeida e José Cardoso, cujo filme $O$ anúncio foi selecionado para representar o país no Festival Internacional de Cinema Amador de Aveiro, em Portugal, e posteriormente premiado. Outros exemplos de filmes importantes na época foram Catembe, de José Faria de Almeida e $\operatorname{Km} 72$, de João Ferreira e Fernando Carneiro, ambos de 16mm, preto e branco, que foram proibidos pela censura do regime colonial português.

Em 1970, o cineasta italiano Franco Cigarini produziu o primeiro documentário sobre a guerrilha em Moçambique, denominado Venti giorni con i guerriglieri del FRELIMO. Cineastas de outros países como União Soviética, Estados Unidos e Iugoslávia também realizaram trabalhos sobre a realidade das zonas controladas pelos guerrilheiros no país. Poucos dias antes da Independência, o cineasta americano Bob Van Lierop rodou A luta continua e o brasileiro José Celso filmou 25.

O primeiro filme de Moçambique independente foi Do Rovuma ao Maputo, do cineasta iugoslavo Popovic, registro da viagem do presidente da FRELIMO, Samora Machel do norte ao sul do país.

Após a Independência, em 1975, o então presidente Samora Machel criou o Instituto Nacional de Cinema (INC) voltado para a formação de cineastas, cujo primeiro diretor foi Américo Soares. O INC tornou-se um "laboratório que aproximou os talentos e visões de inúmeros cineastas, roteiristas, editores, produtores e técnicos 
moçambicanos e estrangeiros" (ARENAS, 2012, p. 75), como Licínio Azevedo, João Ribeiro e Sol de Carvalho, entre outros, e os diretores vanguardistas franceses Jean Rouch e Jean-Luc Godard. Ele priorizava produzir o maior número de filmes que registrassem acontecimentos nacionais, além de estimular a circulação de imagens entre as diversas províncias e grupos étnico-linguísticos e reverter recursos na formação de jovens profissionais na área.

O Instituto tornou-se também um importante centro de produção de cinejornais, documentários e alguns longas-metragens. De lá surgiu seu projeto mais conhecido, denominado Kuxa Kanema (O nascimento do cinema), que é considerado pelos críticos e historiadores do cinema africano "a tentativa mais bem sucedida na criação de um cinema que atendia aos interesses do povo africano" (ARENAS, 2012, p. 77). O projeto envolvia a produção de cinejornais semanais exibidos em salas ou através de vans em todo o país, documentários de curta duração e longas-metragens e tinha a direção de Fernando Silva, textos do poeta Luis Patraquim e locução de Américo Soares.

$\mathrm{Na}$ segunda metade de 1976, o INC produziu e lançou seu primeiro documentário de longa metragem: Ano 1 da Independência Nacional, dirigido por Fernando Silva, que foi exibido em cinemas por todo o país e foi muito bem recebido pelo público.

Em 1978, o Centro de Estudos de Comunicação da Universidade Eduardo Mondlane e o Centro de Técnicas Básicas de Aproveitamento dos Recursos Naturais iniciaram em parceria com o Musée de l'Homme de Paris, o "Projeto Super 8", dirigido por João Azevedo e Borges Coelho, que visava, através de técnicas básicas, resolver problemas concretos das comunidades e usar o cinema para complementar o processo ensino-aprendizagem. Entretanto, o avanço da guerra na década de 1980 interrompeu o andamento destas atividades.

Dentre os cineastas moçambicanos importantes, destaque para o brasileiro, nascido no Rio Grande do Sul, Licínio Azevedo, radicado em Moçambique em 1975. Desde o início da década de 1990, ele tem mantido um bom nível de produtividade de documentários e curtas-metragens de ficção. Licínio trabalhou no Instituto Nacional de Cinema, ao lado de Ruy Guerra e Godard. Também atuou na televisão e fundou uma empresa de produção cinematográfica, a Ebano Multimedia. Ele dirigiu, por exemplo, $A$ árvore dos antepassados (1995); A guerra da água (1995); Rosa Castigo (2002); Desobediência (2002); Night stop (2002); O acampamento da desminagem (2004); O grande bazar (2006); Hóspedes da noite (2007), entre outros. 
Ainda hoje há poucos estudos voltados para manifestações artísticas africanas em língua portuguesa, como a literatura e o cinema, principalmente dentro do meio acadêmico. Percebe-se ainda a insuficiência de uma recepção crítica volumosa e atualizada, bem como de debates regulares sobre o que tem sido feito no continente africano do ponto de vista cultural.

Como afirma Mirian Tavares (2012, p. 2), "partindo da premissa que o cinema, como forma visível, e mais do que apenas uma forma cultural e/ou artística, é também uma maneira de se organizar e de se refletir sobre o mundo", estudá-lo pode ajudar-nos a compreender melhor as culturas africanas dos países de língua portuguesa, já que o cinema é

um dos mais importantes repositórios de imagens a que podemos ter acesso. Não só pelo que mostra, mas também por aquilo que ele diz. Assim, se o filme tem servido, desde o início, para organizar a nossa experiência do mundo, é legítimo recorrer a ele para entender melhor a construção do imaginário de um povo ou de uma nação (TAVARES, 2012, p. 2).

Percebe-se, principalmente na produção fílmica contemporânea em Moçambique, uma preocupação justamente com a qualidade técnica, com os elementos fotográficos, o enquadramento, os planos, etc., por exemplo, na obra de João Ribeiro, Sol de Carvalho e no próprio Licínio Azevedo. Assim, justifica-se pensar o cinema africano de língua portuguesa como cinema, de fato, pois "ao dar visibilidade ao invisível ou voz ao silencioso, o cinema africano deve proceder de tal maneira que o casamento entre forma e conteúdo crie uma harmonia prazerosa" (THIONG'O, 2007, p. 28).

O cinema africano é "fundamentalmente uma atividade e uma experiência póscolonial" (ARMES, 2007, p. 143). Nesse sentido, cabe tecer algumas considerações sobre esta terminologia. O pós-colonial, de acordo com Stuart Hall (2008, p. 96), caracteriza-se pela passagem de uma configuração histórica de poder para outra. Aliás,

não se trata apenas de ser "posterior" mas de "ir além" do colonial (...). A questão mais delicada é saber se ambos poderiam ser realmente separados, e o que tal separação significaria para a forma como a própria "colonização" estaria sendo conceituada. O "colonialismo" se refere a um momento histórico específico (um momento complexo e diferenciado, como tentamos sugerir); mas sempre foi também uma forma de encenar ou narrar a história, e seu valor descritivo sempre foi estruturado no interior de um paradigma teórico e definidor distinto. A própria sucessão de termos que foram cunhados para se referir a esse processo - colonização, imperialismo, neocolonial, 
dependência, Terceiro Mundo - demonstra a intensidade com a qual uma importante bagagem política, conceitual e epistemológica estava atrelada a cada um desses termos descritivos aparentemente inocentes (HALL, 2008, p. 111).

Assim como Hall, Walter Mignolo (1996, p. 9) acredita que o "pós" do póscolonial é notavelmente diferente dos outros "pós" da crítica cultural contemporânea. Para ele, a pós-colonialidade (tanto em termos de situação ou condição, como de produção teórica e discursiva) tende a estar conectada com as experiências do Terceiro Mundo. A ambiguidade semântica do pós-colonialismo é também reforçada pela professora portuguesa Inocência Mata. Para ela, alguns o entendem como "referente à situação em que vive(ra)m as sociedades que emergiram depois da implantação do sistema colonial" (MATA, 2011, p. 1), enquanto que para outros o "pós" do significante "colonial" refere-se a sociedades "que começam a agenciar a sua existência com o advento da independência" (MATA, 2011, p. 1).

Os cinemas africanos refletem "as intensas mudanças culturais e sociais que vêm ocorrendo nas nações africanas como consequência de reviravoltas políticas e econômicas que afligem constantemente o continente" (BOUGHEDIR, 2007, p. 37). Mahomed Bamba lembra que a crítica ocidental "elaborou e projetou suas próprias representações imaginárias sobre as produções africanas" (2007, p. 84), o que consequentemente estimula o desenvolvimento de um olhar preconceituoso, ao mesmo tempo que rejeita as novidades oferecidas pelos cineastas africanos. Os filmes africanos apenas ganham um olhar diferenciado,

só começam a ser apreciados essencialmente como são, isto é, como imagens decorrentes de uma outra cultura (e não de uma cultura imaginada e pré-fabricada pelo ocidente), quando emerge um novo público que não compartilha das categorias da crítica eurocêntrica (BAMBA, 2007, p. 85).

De fato, as discussões sobre a pós-colonialidade, segundo Edward Said, surgem num contexto onde

a Europa e o Ocidente já não são mais padrões indiscutíveis para o resto do mundo. O desmantelamento dos grandes impérios coloniais depois da Segunda Guerra Mundial diminuiu a capacidade da Europa de iluminar intelectual e politicamente o que se costumava denominar de regiões obscuras da Terra. Com o advento da Guerra Fria, a emergência do Terceiro Mundo e a emancipação universal sugerida, se não decretada, pela presença das Nações Unidas, as nações e 
tradições não europeias pareciam agora dignas de atenção séria (SAID, 2005, p. 37).

Sendo assim, a crítica pós-colonial propõe-se então a

desfazer o eurocentrismo, mantendo, porém, a consciência de que a pós-colonialidade não se desenvolve numa distância pan-óptica em relação à história: a pós-colonialidade existe como um "depois" depois de ter sido "trabalhada" pelo colonialismo. O espaço ocupado por esta enunciação de discursos de dominação não se localiza nem dentro nem fora da história de dominação europeia, mas antes numa relação tangencial com ela (ALMEIDA, 2007, p. 28).

Se por um lado essas relações não veem mais sob o enfoque de uma desigualdade de poder e de exploração entre as sociedades colonizadoras e as colonizadas, agora elas se apresentam deslocadas e reencenadas sob a forma de lutas entre forças sociais locais, sob a faceta de contradições internas, que, consequentemente, podem gerar desestabilizações no interior da sociedade descolonizada, ou entre ela e o sistema global como um todo.

O cinema desenvolvido em África tem se caracterizado justamente como instrumento de luta contra todas as formas de controle da liberdade, oriundas do processo de colonização europeia que afetou o continente como um todo, em todos os níveis: econômico, cultural, político e psicológico, assim como na construção de sua própria autoimagem e das suas sociedades:

Mesmo que o Estado pós-colonial se veja como independente, ele ainda sofre de todas as cicatrizes coloniais em sua psique coletiva. A arte cinematográfica tem o dever de desmascarar a descolonização parcial da maioria dos Estados na África. (...) A descolonização não pode ser parcial: ela deve ser total para todos os setores da população e em todos os níveis (THIONG'O, 2007, p. 31).

A partir daí, emergem novos e fecundos pontos de vista, que vieram contribuir para o desenvolvimento de uma crítica a conceitos que cristalizaram a imagem dos países colonizados como "subdesenvolvidos", "periféricos", "de Terceiro Mundo", "desprovidos de cultura própria". Assim, a produção de filmes dentre deste espaço resulta, de fato, de uma "problemática de afirmação cultural e de identidade" (BAMBA, 2007, p. 19).

Moçambique destaca-se na história do cinema africano pós-colonial por apresentar uma "infraestrutura de cinema nacional desvinculada do circuito cinematográfico comercial global e ao serviço da nação marxista que emergiu após o 
colonialismo português" (ARENAS, 2012, p. 75). Sua nova concepção de cinema visou outro público alvo, não mais a burguesia colonial estrangeira; fazia-se cinema agora para o povo moçambicano, em sua maioria constituído por camponeses analfabetos (naquela época a taxa de analfabetismo era de 93\%). Houve então uma preocupação por parte dos cineastas de adequar a linguagem cinematográfica para esse público.

O cinema põe também em debate outros conceitos muito discutidos, principalmente pelo seu caráter ambíguo, dentro do campo da crítica cultural, e que tem uma função importante nesse trabalho proposto: o de representação. Sua vasta projeção no campo dos estudos literários e culturais consequentemente possibilitou que o termo fosse afetado por certa polissemia. Uma possibilidade de definição, ou melhor, de atribuição do termo, acontece quando ele refere-se à representação do real. A ideia de representação defronta-se e/ou aproxima-se da de imitação, que vem desde a Antiguidade clássica, com Platão e Aristóteles. A discussão prolonga-se até os tempos mais atuais com Eric Auerbach, filólogo e crítico literário alemão, que em seu famoso livro Mimesis, propõe analisar a questão da representação da realidade e a relação do texto literário com o mundo; Jacques Derrida que, por exemplo, foi um dos estudiosos que se contrapôs radicalmente à concepção clássica do termo e Michel Foucault que em As palavras e as coisas explica que a linguagem não é a representação do real, pois o signo verbal é arbitrário em relação aos objetos a que ele refere.

Para Kandall Walton, "quase todos os filmes são representações; mais especificamente, são representações visuais ou representações que afiguram, são imagens" (2005, p. 105). A imagem é seu constituinte primordial. Jacques Aumont, no livro A imagem, por exemplo, faz uma síntese notável sobre a percepção, seus componentes fisiológicos e psicológicos. A discussão sobre o que as imagens e "especialmente como se diferenciam das descrições é bem mais complexa do que pode parecer à primeira vista" (WALTON, 2005, p. 106). Esta palavra e seus derivados (imaginação e imaginário) têm origem do latim imago-ginis e apresenta diversas significações, como "vulto, representação, (...) ou figura real ou irreal que evocamos ou produzimos com a imaginação", segundo Octavio Paz (1982, p. 37). Para ele, "as imagens são produtos imaginários” (PAZ, 1982, p. 37) já que cada imagem, consequentemente, contém muitos significados "contrários ou díspares, aos quais abarca ou reconcilia sem suprimi-los" (PAZ, 1982, p. 37).

O imaginário pode ser concebido "como o lugar de produção de sentido, aquilo que faz significar" (CUNHA, 2006, p. 14). Ele está no campo das representações, mas como uma "tradução não reprodutora, e sim, criadora, poética. É parte da representação, 
que é intelectual, mas a ultrapassa" (LE GOFF, 1994, p. 13-14). Para Aumont, o imaginário é "o domínio da imaginação, compreendida como faculdade criativa, produtora de imagens interiores eventualmente exteriorizáveis (AUMONT, 1993, p. 118).

Diferente de outras narrativas fílmicas da autoria de Licínio Azevedo, $O$ grande bazar está ambientado no espaço urbano, mais especificamente na capital moçambicana, Maputo. O mercado popular é o palco onde se desenrola a história dos personagens. Alimentos típicos, temperos, artigos religiosos, artesanato, frutas, legumes e verduras, carnes, peixes e até animais vivos, tudo isso pode ser encontrado em feiras e mercados populares espalhados pelo mundo. Nos mercados ao ar livre típicos da África, cada objeto pode ser vendido, reciclado ou reutilizado.

Este espaço está carregado de imagens fortes, cores vivazes, cheiros variados e pela diversidade de pessoas, o que abre um leque de possibilidades para a criação artística, e como tal, torna-se objeto de interesse para fotógrafos e cineastas. Assim, o filme apresenta um colorido muito característico do continente africano, que contrasta com a realidade retratada, marcada principalmente pela pobreza. Os personagens com suas vestes notadamente monocromáticas destacam-se no caos pintado pela tela, o que cria uma atmosfera mais alegre e descontraída ao filme. Aliás, a diversidade de tipos humanos é um caso à parte dentro dos mercados populares que, no filme, reflete uma parte significativa da sociedade moçambicana, como o exótico fotógrafo retratista, conhecido como Magerman, que tinha uma técnica curiosa ao utilizar um buraco na unha do dedão como visor; ou Kadapé, um sapateiro que consertava e vendia sapatos com combinações criativas.

O grande bazar é um filme classificado como curta-metragem. De acordo com Francis Vanoye (2009, p. 114), as formas fílmicas curtas

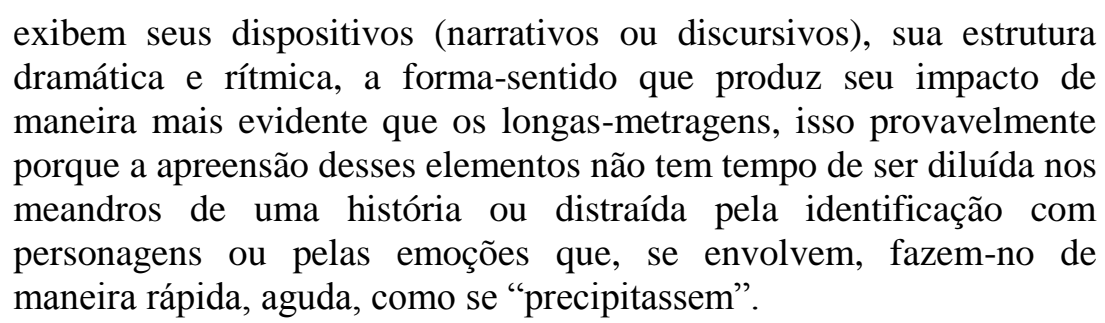

Elas oferecem boas bases para uma análise: "a forma global do filme curto se oferece à percepção e, consequentemente, a uma análise mais fácil. Observa-se, aliás, que grande número de curtas-metragens são construídos a partir de formas simples ou 
de configurações retóricas bem discerníveis" (VANOYE, 2009, p. 114). Apesar disso, o filme apresenta também características bem próximas à linguagem documental.

Assim como a fotografia ou a direção de arte, o universo sonoro é um elemento determinante na composição estética da linguagem cinematográfica, nem sempre bem definido ou explorado nos diversos cursos ou escolas audiovisuais. A partir da análise do desenho de som do filme, será detalhado o trabalho do editor de som ou sound designer, desde o conceito definido pelo diálogo com o diretor do filme até a edição das pistas que serão preparadas para a mixagem. Em $O$ grande bazar, a música original tenta imprimir o mesmo tom alegre e suave das imagens. Composta e representada por Chico Antonio, ela é constituída por uma base harmônica “acompanhada de uma percussão delicada e um baixo elétrico" (ARENAS, 2012, p. 92).

Outros aspectos a serem observados referem-se à própria estrutura da narrativa: o cenário (os elementos do cenário, o cenário com relação aos acontecimentos, a função do cenário na cena), os personagens (física e implicitamente presentes, as relações que os circulam), o enredo, entre outros. Em relação ao enredo, o filme conta a história de amizade entre dois garotos, Paíto e Xano, oriundos de classes sociais diferentes. Paíto é pobre e ajudava a mãe a vender os quitutes que ele produzia. Ele demonstrava desde o início ter um bom tino comercial. Na falta de farinha para continuar preparando suas iguarias, sua mãe dá-lhe uma quantia em dinheiro para comprar o que necessitava, mas o menino não encontrou o produto. No intuito de multiplicar o dinheiro, ele comprou um maço de cigarros para vender as unidades. Entretanto, quando começar a despertar o interesse dos clientes, ele foi roubado por um grupo de ladrões. Paíto então se encontrou sem o dinheiro e sem a farinha. Para resolver tal problema, ele pegou uma condução dirigindo-se a um mercado popular. Lá, ele começou a ganhar dinheiro ajudando as pessoas a carregar suas comprar, além de realizar pequenas compras.

Xano vinha de uma família de classe média. Vivia com a mãe, dona de um salão de beleza, e com o namorado dela, que batia nele. Por este motivo, preferia passar a maior parte do tempo fora de casa, no mercado. Paíto e Xano se encontram e juntos planejam alternativas para ganhar dinheiro.

Percebe-se na obra uma mistura do estilo documentário ou de reportagem com uma filmagem de ficção mais clássica (influência de Godard) subordinada à clareza, à homogeneidade, à linearidade, à coerência da narrativa.

\section{REFERÊNCIAS BIBLIOGRÁFICAS}


ARENAS, Fernando. "Retratos de Moçambique pós-Guerra Civil: a filmografia de Licínio de Azevedo." In: BAMBA, Mahomed; MELEIRO, Alessandra (orgs.). Filmes da África e da diáspora: objetos de discursos. Salvador: EDUFBA, 2012, p. 75-98.

AUMONT, Jacques. A imagem. Trad. Estela dos Santos. Campinas: Papirus, 1993.

BAMBA, Mahomed. "O papel dos festivais na recepção e divulgação dos cinemas africanos.” In: MELEIRO, Alessandra (org.). Cinema no mundo: indústria, política e mercado: África. São Paulo: Escrituras, 2007, p. 79-104.

MARTIN, Marcel. A linguagem cinematográfica. Trad. Paulo Neves. São Paulo: Brasiliense, 2003.

NICHOLS, Bill. “A voz do documentário.” In: RAMOS, Fernão Pessoa (org.). Teoria contemporânea do cinema: documentário e narratividade ficcional. São Paulo: Editora SENAC, 2005, p. 47-67.

O GRANDE bazar. Direção: Licínio Azevedo. Moçambique: Ébano Multimedia, 2006. (56 min).

RIESCO, Beatriz Leal. "A caminho de um amadurecimento na utilização da música no cinema africano: Sembene, Sissako e Sené Absa." In: BAMBA, Mahomed; MELEIRO, Alessandra (orgs.). Filmes da África e da diáspora: objetos de discursos. Salvador: EDUFBA, 2012, p. 101-128.

TAVARES, Mirian. "Cinema africano: um possível, e necessário, olhar." In: Revista Universitária do Audiovisual. Disponível em www.ufscar.br/rua/site/?p=6331 Acesso 22 out. 2012.

THIONG'O, Ngugi Wa. “A descolonização da mente é um pré-requisito para a prática criativa do cinema africano?" In: MELEIRO, Alessandra (org.). Cinema no mundo: indústria, política e mercado: África. São Paulo: Escrituras, 2007, p. 27-32.

WALTON, Kendall. "Sobre imagens e fotografias: resposta a algumas objeções." In:

RAMOS, Fernão Pessoa (org.). Teoria contemporânea do cinema: documentário e narratividade ficcional. São Paulo: Editora SENAC, 2005, p. 105-125. 